\title{
Genetic differentiation of European larch along an altitudinal gradient in the French Alps
}

\author{
Maxime Nardin ${ }^{1} \cdot$ Brigitte Musch $^{2} \cdot$ Yves Rousselle $^{2}$ - Vanina Guérin ${ }^{1} \cdot$ \\ Leopoldo Sanchez ${ }^{1} \cdot$ Jean-Pierre Rossi $^{3} \cdot$ Sophie Gerber $^{4} \cdot$ Sara Marin $^{1,5}$. \\ Luc E. Pâques ${ }^{1} \cdot$ Philippe Rozenberg $^{1}$
}

Received: 9 September 2014 / Accepted: 26 March 2015 /Published online: 30 April 2015

(C) INRA and Springer-Verlag France 2015

\begin{abstract}
- Key message Despite variable dynamics of genetic diversification at the different altitudinal levels, strong gene flow tends to standardize larch genetic diversity: the larch
\end{abstract}

\section{Handling Editor: Ricardo Alia}

Contribution of the co-authors Maxime Nardin is the $\mathrm{PhD}$ student in charge of the study.

Dr. Brigitte Musch supervised the writing of the article, then reviewed and commented on successive drafts of the paper.

Dr. Yves Rousselle reviewed and commented on successive drafts of the paper. Vanina Guerin participated in cambium sampling and development of the genetic markers, supervised and organized the genotyping, and commented on successive drafts of the paper.

Dr. Leopoldo Sanchez participated in the project and trial design and establishment, cambium sampling, and project coordination.

Dr. Jean-Pierre Rossi participated in cambium sampling, designed and helped in performing the spatial genetic analysis (SGS), and reviewed and commented on successive drafts of the paper.

Dr. Sophie Gerber supervised the development of the genetic markers and participated in cambium sampling, trial design and establishment, and project coordination.

Sara Marin participated in the trial design and establishment, increment core and cambium sampling, and microdensity preparation and analysis process. Dr. Luc E. Pâques participated in the trial design and establishment and coordination of the research project, reviewed and commented on successive drafts of the paper, and co-supervised Maxime Nardin.

Dr. Philippe Rozenberg led the project and trial design and establishment, participated in cambium sampling, reviewed and commented on successive drafts of the paper, coordinated the research project, and co-supervised Maxime Nardin.

Philippe Rozenberg

philippe.rozenberg@orleans.inra.fr

1 UR0588 Unité Amélioration Génétique et Physiologie Forestières, INRA Val de Loire Orléans, 2163 avenue de la Pomme de Pin, CS 40001 Ardon, Orléans Cedex 2, F-45075, France

2 Département Recherche et Développement, USC INRA 2030, Conservatoire Génétique des Arbres Forestiers, Office National des Forêts, 2163 Avenue de la Pomme de Pin, CS 40001 ARDON, 45075 Orleans Cedex 2, France forest distributed along the altitudinal gradient can be regarded as a single population.

- Context While in forest tree species many studies focus on the structure of the genetic diversity at the natural range and at the forest stand levels, few studies have worked at intermediate levels like the landscape level.

- Aims We tried to determine to what degree altitude variation can affect the genetic diversity and the local structure of the genetic diversity of European larch (Larix decidua Miller) at the landscape level.

- Methods Using microsatellite markers, we determined the between- and within-plot genetic structure and the spatial genetic structure (SGS) of four altitudinal plots distributed between 1,350 and 2,300 $\mathrm{m}$ a.s.1. in a European larch forest located in the French Alps.

- Results A homogenous neutral genetic structure was detected along this gradient. The intensity of the SGS was found to be stronger at 2,300 $\mathrm{m}$ and decreased at the 2,000-m plot. It was low or non-existent at the 1,700- and 1,350-m altitudinal levels.

- Conclusion Our results suggest that the genetic structure observed at the landscape level in this European larch forest was only slightly affected by climatic variation, human activities, or historical events. However, the variation of intensity of the SGS within the altitudinal plots indicates the existence

3 INRA, UMR CBGP (INRA/CIRAD/IRD/Montpellier Supagro), 755 avenue du Campus Agropolis, CS 30016 F-34988 Montferrier-sur-Lez cedex, France

4 INRA, BIOGECO, UMR 1202, F-33610 Cestas, France

5 Laboratory Evolution \& Diversité Biologique (EDB), Université de Toulouse Paul Sabatier, Office 124, Bat. 4R1, 118 Route de Narbonne, 31062 Toulouse Cedex 09, France 
of variable genetic dynamics, despite the globally uniform genetic structure along the altitudinal gradient.

Keywords Genetic diversity $\cdot$ Spatial genetic structure $\cdot$ Larix decidua $\cdot$ Microsatellite markers $\cdot$ Mountain $\cdot$ Population structure

\section{Introduction}

During the last 25 years, molecular tools have allowed studies of neutral genetic diversity across regions (Alps for example) and ranges of tree populations (Comps et al. 1991; Müller-Starck et al. 1991; Zanetto and Kremer 1995; Collignon and Favre 2000; Scotti et al. 2006; Tollefsrud et al. 2008; Wagner et al. 2012). The main results indicated on the one hand that differentiation among populations was extremely low but on the other hand that intraspecific diversity was high (Hamrick et al. 1992; Hamrick 2004; Maghuly et al. 2006). However, studies using mitochondrial or chloroplast DNA markers found a higher genetic differentiation within the species area in the case of a maternal inheritance (Newton et al. 1999; Petit et al. 2005). Furthermore, combined progress in both molecular markers and statistical tools has permitted a focus on finer-scale spatial genetic structure: they have shown the importance of gene flow and its impact on the genetic structure at a local scale (Vekemans and Hardy 2004; Hardy et al. 2006). Even if the limitation of gene flow remains the main reason for this structure, natural selection, historical events, and anthropic effects could also influence the spatial genetic structure (SGS) of populations (Vekemans and Hardy 2004; Troupin et al. 2006; Mathiasen and Premoli 2013). The SGS are often strongly determined by the ability of each species to disperse seeds (Hardy et al. 2006). While a weak structure or no genetic differentiation between populations is often observed, a majority of studies show a significant finescale spatial genetic structure with a positive relationship between spatial proximity and relatedness. Like the genetic differentiation at the level of the species area, the intensity of SGS varies with the mode of DNA inheritance (Scotti et al. 2008).

Compared to the number of studies focusing on the two extremes of the geographical scale (species distribution area and forest stand), studies at the landscape level are much scarcer. Generally, they focus on locations having high environmental variation in order to determine how strongly this variation influences neutral genetic diversity (Sork et al. 1999; Manel et al. 2010). In this context, it is not surprising that the majority of the studies at the landscape level were conducted along altitudinal gradients (Ohsawa and Ide 2008; Alberto et al. 2010; Unger et al. 2011). Altitudinal gradients present the strongest environmental variations on a short geographic distance (temperature decreases by $5.5^{\circ} \mathrm{C}$ per kilometer with altitude (Körner 2007) but only by $0.49^{\circ} \mathrm{C} / 100 \mathrm{~km}$ in France with latitude), and they allow a comparison of genetic diversity at different scales along the gradient. However, the patterns of genetic diversity variation described depend not only on species autecology but also on the history of the population (species dynamics and human activities). Natural and anthropogenic constraints affect evolutionary processes which in turn shape genetic diversity. In this article, our objective is to evaluate between and within-population neutral genetic diversity of an anemophilous species in the French Alps at the landscape level: European larch (Larix decidua Mill.).

Four evolutionary processes may influence genetic diversity: mutation, migration, genetic drift, and natural selection.

For forest trees, gene flow occurs through both pollen and seed dispersion and may be directional along altitudinal gradients due to gravity and wind flow. Environmental variation, like climate, can also affect the evolutionary process of migration. If differences in climatic conditions are strong enough, asynchronous flowering may lead to some degree of population isolation along altitudinal gradients (Alberto et al. 2010). Genetic drift may occur at the higher elevation either when the number of individuals is low, when the trees come from a recent colonization (founder effect), or when they are isolated in terms of gene flow. Moreover, human interventions are not homogeneous along the altitudinal gradients and generally occur more at lower altitude. Silviculture may influence the evolutionary processes during thinning, inducing an effect similar to the genetic drift. Finally, the strong environmental variation along an altitudinal gradient can induce natural selection. At each altitudinal level, natural selection will eliminate the deleterious alleles and increase the frequency of alleles associated with increased fitness. If there is linkage disequilibrium between a selected gene and a neutral marker, the later one will be affected in the same way as the selected gene.

Many studies focused on the study of genetic diversity of plant species along altitudinal gradients. Reviewing 42 of them, Ohsawa and Ide (2008) found four different patterns of altitudinal changes in the genetic diversity of plant species, with approximately the same number of occurrences for each pattern: (1) the genetic diversity increases from the low and high altitudes to the middle of the gradient, (2) the genetic diversity decreases from low to high altitude, (3) the genetic diversity decreases from high to low altitude, and (4) the genetic diversity is unaffected by altitudinal variation. Since then, several other studies in forest trees found no variation of genetic diversity along altitudinal clines (Navascues et al. 2008; Alberto et al. 2010; Nishimura and Setoguchi 2010; Shanjani et al. 2011; Unger et al. 2011; Kurt et al. 2012; Radu et al. 2014) or a decreased genetic diversity at the higher altitude (Mathiasen and Premoli 2013).

Gene flow, natural selection, and genetic drift may also influence the spatial structure of genetic diversity at each altitudinal level. Theoretically, the harsh and cold high altitude environment may strongly affect tree survival and reproduction and thereby SGS (Unger et al. 2011). Moreover, a variation in tree 
density (i.e., number of trees per hectare) between the altitudinal levels can also affect the within-altitudinal level seed flow by changing the opening of the canopy and the between-tree competition. In the same vein, a variation in the number of trees between the altitudinal levels can also affect the SGS by the effect of drift, especially if the gene flow is low (Lefèvre et al. 2013). Finally, the kinship and spatial relationships at intraaltitudinal levels may be modified if individuals are nonrandomly removed from the population, either as the result of natural selection or of human intervention.

While genetic diversity has been extensively studied in forest trees, only very few studies focused on how SGS could vary with altitude (Unger et al. 2011; Mathiasen and Premoli 2013). In the particular case of L. decidua, to our knowledge, two studies examined genetic diversity along an altitudinal gradient (Zhao et al. 2001; King et al. 2013). None of them studied SGS variation with altitude.

In this paper, we use a European larch altitudinal gradient (L. decidua Mill.) in the French Alps to evaluate the importance of between and within-population genetic diversity at the landscape level. In the French Alps, the natural populations of larch are distributed over altitudinal gradients extending from 1,200 to $2,500 \mathrm{~m}$ a.s.l. The corresponding severe temperature decrease strongly regulates tree functioning and impacts population adaptation: for example, Moser et al. (2010) showed that larch bud flushing was delayed by approximately 3.6 days/ $100 \mathrm{~m}$ of elevation. Flowering preceding and paralleling bud flushing might be asynchronous between altitudinal levels and could affect gene flow. The native larch forest has been used and managed for centuries. According to the local forest service (C. Ruth and F. Bottin, personal communication), larch is locally preferred to any other conifer species because of its appreciated wood and because pasture is more abundant and of better quality for grazing domestic animals under its light shade. In this study, we describe the neutral genetic diversity along a 1, 000-m altitudinal gradient in a larch forest in the Alps near Briançon. The results indicate how the intensity of genetic drift is likely to have an impact on the genetic diversity and on its structure along this altitudinal gradient. Since no direct measurement of gene flow was available, we indirectly discussed their intensity using an approach based on $G_{\mathrm{ST}}$ estimation.

More specifically, we address the following questions: (1) Is there a significant neutral genetic differentiation along the altitudinal gradient studied, and if so, what is the intensity of this differentiation? (2) Is there variable SGS within each altitudinal plot?

\section{Material and methods}

\subsection{The altitudinal gradient}

The altitudinal gradient considered in this study is located at Villar-St-Pancrace ( $44^{\circ} 52^{\prime} \mathrm{N}, 6^{\circ} 41^{\prime} \mathrm{E}$; Hautes-Alpes, France) in the French Alps. The site corresponds to a continuous natural population of European larch (L. decidua). Four plots have been delimited along an altitudinal gradient at 1,350, 1,700, 2, 000 , and 2,300 $\mathrm{m}$. The two extreme plots represent approximately a $5{ }^{\circ} \mathrm{C}$ mean annual temperature difference (period, 1967-2007; source Météo-France). Conventional soil analyses along this altitudinal gradient showed a greater fertility and water availability at the intermediate altitude. During the period 1967-2007, total annual precipitation ranged from 425.5 to 1 , $078.2 \mathrm{~mm}$ in Briançon (44 ${ }^{\circ} 53^{\prime} \mathrm{N}, 6^{\circ} 38^{\prime} \mathrm{E}$ ), where the nearest Météo-France climatic station is located. Each plot comprises of 198 to 217 contiguous trees. Girth at breast height (BH) was measured on all trees (in September 2008, for plots 2,300, 2, 000 , and $1,700 \mathrm{~m}$; in July 2009 , for plot $1,350 \mathrm{~m}$ ) as well as the dominant height of the 100 biggest trees per ha. A phenotypic variation was observed between these different plots for mean height and mean $\mathrm{BH}$ diameter, with the maximum values occurring at the intermediate altitudinal plot of $1,700 \mathrm{~m}$. A short description of the plots is given in Table 1 .

A microdensitometry approach was used for counting the number of rings and thereby for estimating the age of the trees. Pith-to-bark radial increment cores were collected at breast height using a 5.5-mm Pressler increment borer following a constant north-south orientation for the all trees studied. We assume that the number of rings observed in an increment core is an estimate of the age of a tree. Hence, the study trees were selected according to the quality of the increment cores and of the microdensity profiles obtained from these cores: we selected trees with complete increment cores passing as close as possible to the pith, in order the estimate tree age as precisely as possible. The samples were dried and then X-rayed (Polge 1966). Finally, the X-ray films were scanned at 4,000 dpi in order to acquire microdensity profiles using the software WinDENDRO (WinDENDRO 2008e Regent Instruments Canada Inc.). The microdensity profiles were cross-dated (Interdat.exe, version 1.1, Dupouey J.L., unpublished), and the number of rings contained in each increment core was counted.

\subsection{Cambium sampling and DNA isolation}

Bark disks with vascular cambium were collected with a 1.5$\mathrm{cm}$-diameter leather puncher from all trees from the four plots with $\mathrm{BH}$ circumference bigger than $25 \mathrm{~cm}$, during spring 2009 at 1,350, 1,700, and 2,000 m plots and summer 2010 at plot $2,300 \mathrm{~m}$. The samples were placed directly in liquid nitrogen and then stored at $-80{ }^{\circ} \mathrm{C}$ in the laboratory until DNA isolation. The cambium was isolated by scratching, and the total genomic DNA was extracted according to the protocol suggested by NucleoSplin Plant II (MachereyNagel). The genotypes of 788 individuals out of 821 were successfully determined using 13 nuclear simple sequence repeats (nSSR). These nSSR were grouped in two multiplexes 
Table 1 Plot and site characteristics. The value in parentheses is the standard error

\begin{tabular}{|c|c|c|c|c|}
\hline & $\begin{array}{l}\text { Plot } \\
2,300 \mathrm{~m}\end{array}$ & Plot $2,000 \mathrm{~m}$ & $\begin{array}{l}\text { Plot } \\
1,700 \mathrm{~m}\end{array}$ & Plot $1,350 \mathrm{~m}$ \\
\hline Range of altitude (m) & $2,357-2,299$ & $2,023-1,988$ & $1,683-1,640$ & $1,373-1,341$ \\
\hline Mean annual temperature $\left({ }^{\circ} \mathrm{C}\right)$ & 2.92 & 4.46 & 6.32 & 7.66 \\
\hline $\begin{array}{l}\text { Mean temperature of the } \\
\text { warmest month, July }\left({ }^{\circ} \mathrm{C}\right)\end{array}$ & 10.95 & 12.95 & 15.37 & 17.09 \\
\hline $\begin{array}{l}\text { Mean temperature of the } \\
\text { coldest month, January }\left({ }^{\circ} \mathrm{C}\right)\end{array}$ & -3.73 & -2.72 & -1.49 & -0.61 \\
\hline Average number of frosty days & 208 & 192 & 170 & 154 \\
\hline Soil type & Calcisol & $\begin{array}{l}\text { Eutric Brunisol/ } \\
\text { Calcisol }\end{array}$ & Colluviosol & $\begin{array}{l}\text { Regosol/ } \\
\quad \text { Colluviosol }\end{array}$ \\
\hline Number of trees & 198 & 217 & 206 & 200 \\
\hline Plot size $\left(\mathrm{m}^{2}\right)$ & 5,429 & 7,540 & 5,815 & 8,704 \\
\hline Plot density (no. trees/ha) & 365 & 288 & 354 & 230 \\
\hline Mean height (m) & $16.21( \pm 2.19)$ & $25.31( \pm 2.76)$ & $26.71( \pm 2.93)$ & $23.79( \pm 2.64)$ \\
\hline $\begin{array}{l}\text { Mean breast height } \\
\text { circumference }(\mathrm{cm})\end{array}$ & $79.3( \pm 27.4)$ & $98.6( \pm 32.8)$ & $105.1( \pm 34.4)$ & $107( \pm 25.4)$ \\
\hline $\begin{array}{l}\text { Number of rings in the } \\
\text { increment core (age estimation) }\end{array}$ & $95.7( \pm 34.1)$ & $134.0( \pm 48.8)$ & $133.2( \pm 46.1)$ & $143.7( \pm 15.5)$ \\
\hline
\end{tabular}

The climatic data are given for the period 1967-2007 (source Météo-France) newly developed by Wagner et al. (2012). PCR and cycle amplifications were performed according to Wagner et al. (2012). For both multiplexes, reactions were carried out using a DNA thermal cycler (GeneAmp, PCR System 9700, AB Applied Biosystems). Controls were placed on different amplifications to help with determining and confirming the repeatability. Three microliters of PCR product (diluted 1/30) was added to $7 \mu \mathrm{l}$ formamide (Life Technology) and $0.5 \mu \mathrm{l}$ GeneScan 600 LIZ (Life Technology) and migrated on ABI3100 (Applied Biosystems). The results were analyzed using GeneMapper v3 (Applied Biosystems). The binning of the microsatellites markers was performed using the software Autobin (https://www4.bordeaux-aquitaine.inra.fr/biogeco/ Ressources/Logiciels/Autobin).

\subsection{Discarding markers with null alleles}

The algorithm of Dempster et al. (1977) was used to estimate the null allele frequencies among markers. This methodology was implemented in the software GENEPOP 4.0 (Rousset 2008). This statistical approach gives similar results to direct comparison between the maternal alleles and offspring as shown in Oddou-Muratorio et al. (2008). The established procedure allowed detection of the percentage of null allele frequencies at each plot. In this study, we removed the loci exhibiting more than $8 \%$ of null alleles on average.

\subsection{Statistical analyses}

The software GenAlEx v6.4 (Peakall and Smouse 2006) was used to estimate allele frequencies and standard diversity indices including the number of alleles $\left(N_{\mathrm{a}}\right)$, the effective number of alleles $\left(N_{\mathrm{e}}\right)$, observed $\left(H_{\mathrm{o}}\right)$ and expected heterozygosity $\left(H_{\mathrm{e}}\right)$, as well as private alleles $(n)$. Allelic richness was computed using the rarefaction method (El Mousadik and Petit 1996) with the software HP-Rare 1.1 (Kalinowski 2005) and calculated for the smallest number of alleles common to all microsatellite markers and all altitudinal plots (i.e., using a fixed sample size of 346 gene copies).

Tests for linkage disequilibrium at the significant level 0.001, deviations from Hardy-Weinberg equilibrium at each locus, and estimation of the within-population inbreeding coefficient $\left(F_{\text {IS }}\right.$ index: $\left.F_{\text {IS }}=1-H_{\mathrm{o}} / H_{\mathrm{e}}\right)$ were performed with Arlequin 3.5 (Excoffier et al. 2005). Between-population structure was highlighted by an analysis of molecular variance (AMOVA, implemented in Arlequin 3.5). Population differentiation was tested by the coefficient of genetic differentiation $G_{\mathrm{ST}}$ (Nei 1973), estimated with R software using the Package DEMEtics. The significance of this index was tested using 1,000 bootstraps resampling, and the $p$ values were adjusted by Bonferroni correction for pairwise altitudinal plot differentiation. In addition, $G_{\text {ST }}^{\prime}$ and Jost's $D$ were estimated. But because the results are being very redundant with $G_{\mathrm{ST}}$, they are not presented in the article.

Here, the SGS was used to observe the isolation by geographic distance within each altitudinal plot. We used the pairwise kinship coefficients $F_{i j}$ (Loiselle et al. 1995) to assess the autocorrelation, and the computations were done using the software SPAGeDi v1.2 (Hardy and Vekemans 2002). Each plot was separately analyzed. The correlograms were computed for 11 distance lags of $10 \mathrm{~m}$ (Fig. 2). To test if there is a significant isolation by geographic distance within each altitudinal plot, envelopes representing departure from randomness at $95 \%$ were positioned in the correlograms. These envelopes were 
obtained by performing 1,000 randomizations. Moreover, intensity of SGS was evaluated by a regression test of pairwise kinship coefficient by the logarithm of geographic distance in meters. This test was performed in SPAGeDi v1.2.

\section{Results}

\subsection{Age of the trees}

The age distribution varied among the four plots (Fig. 1). The younger trees were found at the highest altitude (95.7 years old on average); the age distributions were more or less the same in the three other plots (from 133.2 to 143.7 years old; Table 1). One individual of the 2,000-m plot was significantly older (375 years old; Fig. 1). The age of the trees appeared much more uniform in the lowest plot as indicated by a lower standard deviation (Table 1).

\subsection{Markers retained for the analysis}

Two markers, Ld_45 and Ld_101, showed a large amount of null alleles (average percentage of respectively 19.7 and $11.8 \%$, results not shown) and were therefore removed from the subsequent analyses. The estimated average percentages of null alleles for the 11 remaining microsatellite markers were less than $8 \%$.

\subsection{Overall genetic diversity}

The results of the genetic diversity analysis per microsatellite loci were summarized in Table 2 . The $11 \mathrm{SSR}$ revealed a total of 125 alleles across the 788 individuals. In addition, the mean

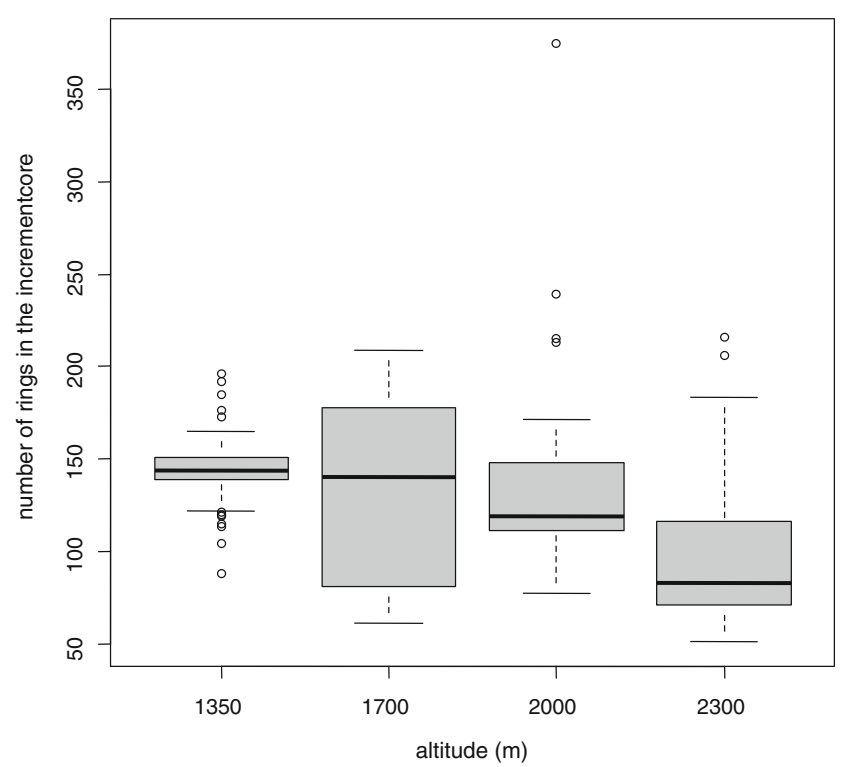

Fig. 1 Descriptive statistics for the age of the trees (number of rings in the increment cores) within the four altitudinal plots number of alleles across all loci was equal to 11.36 with a range from 4 to 22 . The overall $H_{\mathrm{e}}$ was equal to 0.761 ( $\mathrm{SE}=$ 0.029 ). A moderate variation between loci was observed for the $H_{\mathrm{e}}($ range $=0.57-0.88)$.

\subsection{Genetic diversity at the different altitudinal plots}

For each plot, expected heterozygosity $\left(H_{\mathrm{e}}\right)$ ranged from 0.739 to 0.761 . The number of private alleles was three, two, four, and two for the plots at 2,300, 2,000, 1,700, and $1,350 \mathrm{~m}$, respectively. The inbreeding coefficient $\left(F_{\text {IS }}\right)$ indicated a significant deficit in heterozygosity only at the two intermediate plots (Table 3). However, observed values for $F_{\text {IS }}$ were only slightly significant for the plots at 2,000 and $1,700 \mathrm{~m}(0.020$ and 0.029$)$, with no plots affected by inbreeding.

Seven, zero, one, and one pairs of loci out of 55 possible pairs showed linkage disequilibrium (significance level 0.001 ) at 2,300, 2,000, 1,700, and 1,350 m, respectively. There was no or only very weak linkage disequilibrium between the pairs of loci at the three lowest plots. On the contrary, a significant number of pairs of loci with linkage disequilibrium were detected at the plot 2,300 m.

The greater allelic richness and the largest number of rare alleles were observed at the altitudinal plot $1,700 \mathrm{~m}$ (allelic richness $=10.13$ and 60 rare alleles, Table 4), while the higher plot $2,300 \mathrm{~m}$ had the smaller allelic richness and the smaller number of rare alleles (allelic richness $=$ 9.08 and 48 rare alleles, Table 4). A significant negative SGS was detected at the plots 2,300, 2,000, and 1,350 m with the $95 \%$ envelope approach, and no significant SGS was observed at the plot $1,700 \mathrm{~m}$ (Fig. 2). The intensity of the SGS was stronger at the highest altitude and decreased at the intermediate plot situated at 2,000 $\mathrm{m}$ (slopes are -0.013 and -0.0049 , respectively, with $p$ values inferior at 0.001 ). The intensity of the SGS was low or nonexistent at the two lowest altitudinal levels, 1,700 and 1, $350 \mathrm{~m}$ (slopes are -0.0014 and -0.0025 , respectively; with $p$ values 0.1 and 0.012 ).

\subsection{Genetic differentiation between the four altitudinal levels}

According to the results obtained, thanks to the AMOVA analysis, little genetic variance was explained by the altitudinal effect (contribution to total variance $=1.52 \%$, Table 4 ). Similarly, the $G_{\mathrm{ST}}$ index over all populations was significant but rather low $\left(G_{\mathrm{ST}}=0.0121^{* * *}\right.$, Table 2$)$. These results indicate a very low neutral genetic differentiation along this altitudinal gradient.

A significant genetic differentiation was observed for all pairs of altitudinal levels (Table 5) with the plot at 
Table 2 Standard genetic diversity indices per locus estimated across all the altitudinal plots of the gradient

\begin{tabular}{llllllll}
\hline Locus & $N$ & $N_{\mathrm{a}}$ & $N_{\mathrm{e}}$ & $H_{\mathrm{o}}$ & $H_{\mathrm{e}}$ & $G_{\mathrm{ST}}$ & HWE $p$ value \\
\hline bcLK_189 & 788 & 9 & 3.284 & 0.679 & 0.696 & $0.022^{* * *}$ & $0.0396^{*}$ \\
bcLK_211 & 774 & 16 & 6.906 & 0.842 & 0.855 & $0.010^{* * *}$ & $0.5411 \mathrm{~ns}$ \\
bcLK_228 & 786 & 12 & 2.965 & 0.665 & 0.663 & $0.005^{* * *}$ & $0.1702 \mathrm{~ns}$ \\
bcLK_253 & 788 & 11 & 6.399 & 0.850 & 0.844 & $0.009^{* * *}$ & $0.0745 \mathrm{~ns}$ \\
Ld_30 & 787 & 9 & 4.974 & 0.761 & 0.799 & $0.010^{* * *}$ & $0.0382^{*}$ \\
Ld_31 & 784 & 10 & 4.792 & 0.795 & 0.791 & $0.013^{* * *}$ & $0.8362 \mathrm{~ns}$ \\
Ld_50 & 782 & 8 & 3.116 & 0.662 & 0.679 & $0.027^{* * *}$ & $0.0061^{* *}$ \\
bcLk_263 & 783 & 22 & 8.281 & 0.862 & 0.879 & $0.005^{* * *}$ & $0.011^{*}$ \\
Ld_42 & 787 & 4 & 2.316 & 0.521 & 0.568 & $0.015^{* * *}$ & $0.0135^{*}$ \\
Ld_56 & 788 & 7 & 4.232 & 0.770 & 0.764 & $0.004^{* *}$ & $0.7083 \mathrm{~ns}$ \\
Ld_58 & 784 & 17 & 6.023 & 0.754 & 0.834 & $0.013^{* * *}$ & 0 *** \\
Mean & 784.64 & 11.36 & 4.844 & 0.742 & 0.761 & $0.012^{* * *}$ & - \\
SE & 1.245 & 1.551 & 0.569 & 0.031 & 0.029 & - & - \\
\hline
\end{tabular}

Differentiation between plots is presented by $G_{\mathrm{ST}}$ index and Hardy-Weinberg equilibrium tests

$N$ total number of individuals, $N_{\mathrm{a}}$ number of alleles, $N_{\mathrm{e}}$ number of effective alleles, $H_{\mathrm{o}}$ observed heterozygosity, $H_{\mathrm{e}}$ expected heterozygosity, $H W E$ Hardy-Weinberg equilibrium, $n s$ not significant

${ }^{*} P<0.05,{ }^{* *} P<0.01, * * * P<0.001$, significant $F_{\mathrm{ST}}$ and significant departure from Hardy-Weinberg proportions
2,300 $\mathrm{m}$ being the most differentiated subpopulation for $G_{\mathrm{ST}}$ index.

However, all the observed pairwise $G_{\mathrm{ST}}$ values were small and indicated a low neutral genetic differentiation between the altitudinal levels. The intensity of the genetic differentiation between the altitudinal levels was not related to the geographical distances between the different plots (results not shown).

\section{Discussion}

In this study, we observe a high neutral genetic diversity with a low differentiation between plots along an altitudinal gradient of European larch, as it is often observed in the case of forest trees (Ohsawa and Ide 2008; Alberto et al. 2010; Nishimura and Setoguchi 2010; Unger et al. 2011; Kurt et al. 2012). However, the SGS is significantly different between the four altitudinal plots which suggest variable patterns of intra-plot genetic dynamics at the different altitudinal levels.

\subsection{Quality of the markers}

Population differentiation and genetic distances between populations are overestimated if null alleles exist, especially if the gene flow between populations is low (Chapuis and Estoup 2007). The presence of null alleles can also reduce genetic diversity. However, the conventional estimation of population differentiation by $F_{\mathrm{ST}}$ is only slightly biased when it has an average of 5-8 \% of null allele frequency among loci (Chapuis and Estoup 2007). By following this rule, 11 microsatellite markers

Table 3 Per plot and mean standard genetic diversity indices at each plot

\begin{tabular}{|c|c|c|c|c|c|c|c|c|c|c|c|}
\hline & & $N$ & $N_{\mathrm{a}}$ & Allelic richness & Rare alleles & Private alleles & $N_{\mathrm{e}}$ & $H_{\mathrm{o}}$ & $H_{\mathrm{e}}$ & $F_{\mathrm{IS}}$ & LD \\
\hline \multirow[t]{2}{*}{$2,300 \mathrm{~m}$} & Mean & 175 & 9.091 & 9.08 & 48 & 3 & 4.316 & 0.741 & 0.739 & $-0.0054 \mathrm{~ns}$ & 7 \\
\hline & $\mathrm{SE}$ & & 1.187 & - & & & 0.460 & 0.034 & 0.029 & & \\
\hline \multirow[t]{2}{*}{$2,000 \mathrm{~m}$} & Mean & 210 & 9.727 & 9.71 & 51 & 2 & 4.893 & 0.740 & 0.757 & $0.02 *$ & 0 \\
\hline & $\mathrm{SE}$ & & 1.244 & - & & & 0.617 & 0.038 & 0.033 & & \\
\hline \multirow[t]{2}{*}{$1,700 \mathrm{~m}$} & Mean & 204 & 10.273 & 10.13 & 60 & 4 & 4.735 & 0.739 & 0.761 & $0.0286^{*}$ & 1 \\
\hline & SE & & 1.236 & - & & & 0.513 & 0.029 & 0.027 & & \\
\hline \multirow[t]{2}{*}{$1,350 \mathrm{~m}$} & Mean & 199 & 9.818 & 9.72 & 55 & 2 & 4.669 & 0.749 & 0.745 & $-0.0072 \mathrm{~ns}$ & 1 \\
\hline & $\mathrm{SE}$ & & 1.292 & - & & & 0.612 & 0.034 & 0.034 & & \\
\hline
\end{tabular}

Inbreeding coefficient within plots is presented by $F_{\text {IS }}$ index

$N$ number of individual, $N_{\mathrm{a}}$ number of different alleles, $N_{\mathrm{e}}$ number of effective alleles, $H_{\mathrm{o}}$ observed heterozygosity, $H_{\mathrm{e}}$ expected heterozygosity, $S E$ standard error, $n s$ not significant

$* P<0.05$, significant $F_{\mathrm{IS}}$ 
Table 4 Analysis of molecular variance (AMOVA) between plots and individuals

\begin{tabular}{llllll}
\hline Source of variation & $d f$ & $\begin{array}{l}\text { Sum of } \\
\text { squares }\end{array}$ & $\begin{array}{l}\text { Variance } \\
\text { component }\end{array}$ & $\begin{array}{l}\text { \% of } \\
\text { variation }\end{array}$ & $p$ value \\
\hline Among plots & 3 & 87.253 & 0.0634 & $\mathbf{1 . 5 2}$ & $<\mathbf{0 . 0 0 1}$ \\
Among individuals within plots & 784 & $3,249.057$ & 0.04069 & 0.98 & 0.0567 \\
Within individuals & 788 & $3,201.5$ & 4.06282 & 97.5 & \\
Total & 1,575 & $6,537.81$ & 4.16691 & & \\
\hline
\end{tabular}

The percentage of genetic variation explained by the plot effect and the $p$ value are presented in bold $d f$ degrees of freedom among 13 were retained for the statistical analysis to limit the bias for the estimation of population differentiation. Even if the effective number of alleles observed for the microsatellite markers bcLK_228 and bcLK_263 may be considered low $\left(N_{\mathrm{e}}\right.$ equal to 2.965 and 8.281 for a number of alleles equal to 12 and 22, respectively, Table 2) and even if we remove 2 of the 13 markers, our estimation of $F_{\mathrm{ST}}$ remains robust.

\subsection{Genetic diversity in the larch population}

Overall, the genetic diversity observed in this European larch population $\left(H_{\mathrm{e}}=0.761\right)$ was as high as generally expected in forest tree populations (Hamrick et al. 1992; Hamrick 2004). It is consistent with the observation made by Pluess (2011) for the same species in the Swiss Alps $\left(H_{\mathrm{e}}=0.75\right.$, for the five common out of eight microsatellite markers). For other Larix species, genetic diversity may be either similar as in the case of Larix kaempfer in Japan $\left(H_{\mathrm{e}}=0.73\right.$, for 4 out of 11 common microsatellite markers) (Nishimura and Setoguchi 2010) or lower as observed by Khasa et al. (2006) in Larix lyallii and Larix occidentalis ( $H_{\mathrm{e}}=0.42$ and 0.58 , respectively) in Canada. In this study, the value of the genetic diversity is within the upper range usually detected in trees (on average, $H_{\mathrm{e}}$ equals to 0.68; Nybom (2004)). High rates of genetic diversity are generally explained in forest trees by high population size (Kremer 1994). Hence, no case of reduced population size can be conjectured in our altitudinal gradient.

\subsection{Genetic structure along the altitudinal gradient}

A heterozygosity deficit was observed for 6 out of 11 markers and was confirmed by a significant test of deviation of Hardy-
Fig. 2 Analysis of the spatial genetic structure (SGS) in the four plots along the altitudinal gradient. Loiselle's kinship coefficient $\left(F_{i j}\right)$ is plotted for 11 classes of geographic distance (the gray dotted lines show the $95 \%$ confidence intervals). The figures on the graph represent the numbers of pairs of trees for each class of geographic distance

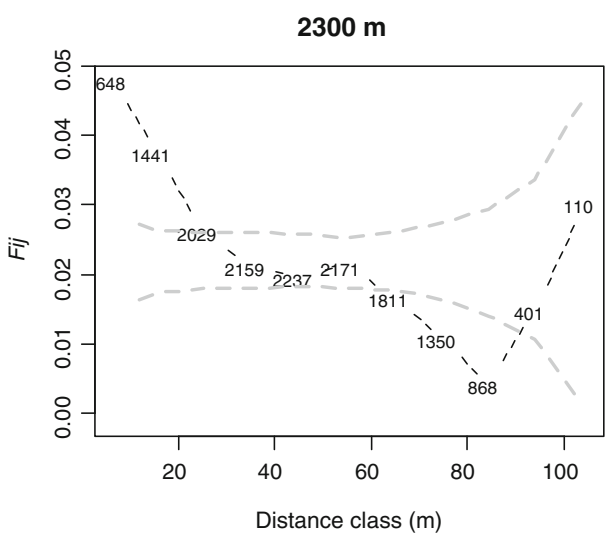

$1700 \mathrm{~m}$

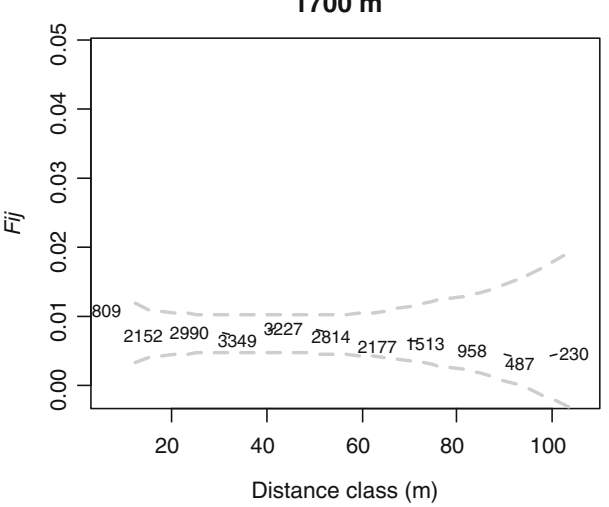

$2000 \mathrm{~m}$

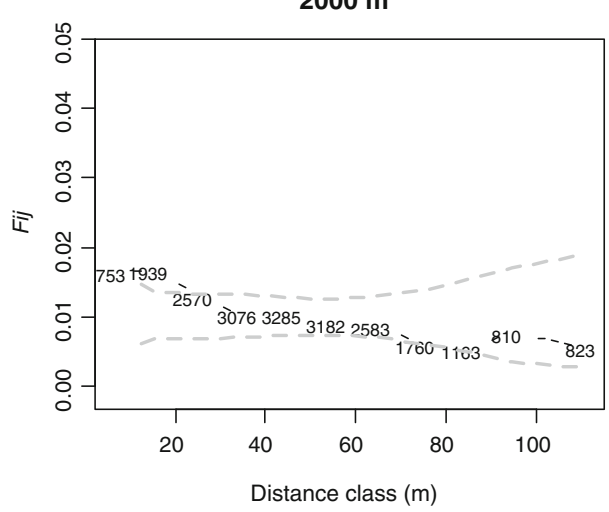

$1350 \mathrm{~m}$

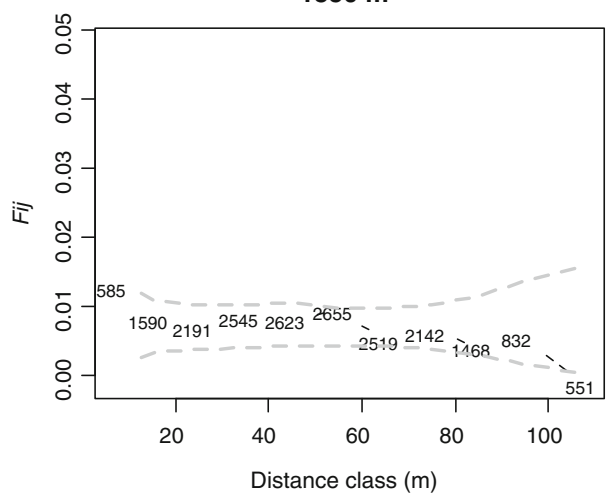


Table 5 Pairwise $G_{\mathrm{ST}}$ between all pairs of four Larix decidua plots along an altitudinal gradient in the French Alps

\begin{tabular}{llll}
\hline & $2,300 \mathrm{~m}$ & $2,000 \mathrm{~m}$ & $1,700 \mathrm{~m}$ \\
\hline $2,000 \mathrm{~m}$ & $0.011^{*}$ & & \\
$1,700 \mathrm{~m}$ & $0.012^{*}$ & $0.006^{*}$ & \\
$1,350 \mathrm{~m}$ & $0.011^{*}$ & $0.007^{*}$ & $0.002 *$ \\
\hline
\end{tabular}

${ }^{*} P<0.001$, significant $G_{\mathrm{ST}}$

Weinberg equilibrium (Table 2). Such deviation could possibly be due to a Wahlund effect caused by genetic subpopulation structure. But the observed levels of heterozygosity deficit were low and only slightly significant except for two markers (Ld_58 and Ld_50, $p$ values $<0.0001$ and 0.0061, respectively, Table 2). For these two markers, a larger deviation from Hardy-Weinberg equilibrium could be explained by the possible linkage disequilibrium between these two markers and putative genes non-neutral to selection.

These low levels of heterozygosity deficit were consistent with a very low genetic structure along the altitudinal gradient as revealed by the AMOVA analysis (contribution to total variance among plots equal to 1.52 ; Table 2 ). The maximum observed pairwise $G_{\mathrm{ST}}$ was also low between plots $\left(G_{\mathrm{STmax}}=\right.$ $0.012 * * *$, Table 5), which confirmed the weak difference among altitudinal levels for genetic diversity.

This low genetic structure is consistent with observations made in other studies on other tree species. Woody species are known to have little neutral genetic differentiation among populations when compared to other organisms. In a review, Hamrick et al. (1992) found a mean value of $G_{\mathrm{ST}}$ equals to 0.085 for species of forest trees observed with allozyme loci. A low differentiation similar to that in our study was observed at the same geographical scale for another larch species (L. kaempferi) along three altitudinal gradients on Mt. Fuji, Japan (Nishimura and Setoguchi 2010). At a broader scale (distribution area level), a low genetic differentiation was observed as well for L. decidua by Maier (1992) $\left(G_{\mathrm{ST}}=0.051\right.$ for seven allozyme loci) and recently by Mosca et al. (2012) $\left(F_{\mathrm{ST}}=0.043\right.$ with several hundreds of SNP markers). King et al. (2013) observed a very low differentiation $\left(F_{\mathrm{ST}}=\right.$ 0.016 ) for a population of European larch distributed along a Swiss altitudinal gradient. However, in another study with European larch along an altitudinal gradient with six subpopulations, Zhao et al. (2001) found higher values of differentiation than King et al. (2013). The larger $F_{\text {ST }}$ values were habitually found between the highest subpopulation and the other ones, probably due to a foundation effect at the highest elevation (ranged from 0.115 to $0.218 ; F_{\mathrm{ST} \text { global }}=0.033$, two allozyme loci).

Therefore, the values of genetic differentiation that we observed (Table 5) were lower than most values reported in other studies. We conclude that the genetic diversity in the population studied is only slightly affected by elevation (and its climatic gradient). This result can be linked to the fourth pattern of genetic diversity identified by Ohsawa and Ide (2008), i.e., the genetic diversity of trees is unaffected by altitudinal variation. As a consequence, the trees along this altitudinal gradient can be considered as a single population. The same pattern was also observed in European larch (King et al. 2013) and in several other forest tree species (Navascues et al. 2008; Alberto et al. 2010; Nishimura and Setoguchi 2010; Unger et al. 2011; Kurt et al. 2012).

Such low values of $G_{\mathrm{ST}}$ between plots along the altitudinal gradient suggest that extensive gene flow along the gradient homogenizes the distribution of genetic diversity and decreases the genetic structure. Compared to other conifers, larch pollen is heavy and has a medium dispersive capacity (the largest share of the pollen is dispersed at a distance lower than $300 \mathrm{~m}$ compared to 880 and $1,000 \mathrm{~m}$, respectively, for spruce and Scots pine (Nanson 2004)). However, if the largest part of the pollen is dispersed at a distance less than $300 \mathrm{~m}$, it is possible that a small portion be dispersed over much larger distances (Austerlitz et al. 2004). Theoretically, this small part may enable a connection between distant plots and play an important role for the homogenization of the genetic diversity in this larch population in the long term. The absence of physical barriers along the gradient facilitates the connection between the distant plots. However, an obvious upward progression of vegetative bud flushing with altitude is observed for L. decidua (Migliavacca et al. 2008; Moser et al. 2010). If we assume that flowering follows the same pattern, flowering asynchrony may limit gene flow with maximum limitation between the two extreme plots.

A recent colonization of the altitudinal gradient would not allow a sufficient time for between-plot differentiation and thus could also explain the low values of $G_{\mathrm{ST}}$ between plots even in absence or with very low homogenizing gene flow between them. However, this second hypothesis is less likely that the presence of extensive gene flow along this gradient because the phylogenetic history of larch in its natural area has been traced up back up to 130,000 years at least (Wagner 2013).

In conclusion, it is most probable that some gene flow contributes to the homogenization of the genetic diversity along the altitudinal gradient and to the low genetic structure. This gene flow is probably strongest between the neighboring plots and progressively decreases with distance between the altitudinal plots. Still it could explain the relatively uniform genetic diversity between the extreme plots.

\subsection{Spatial genetic structure within plots and demographic history of the plots}

To our knowledge, only two studies examined SGS variation with altitude. Unger et al. (2011) did not detect any variation of 
intensity of the SGS along an altitudinal gradient (800 to 1, $600 \mathrm{~m}$ a.s.l.) with Picea abies in the Tyrol, Austria. Mathiasen and Premoli (2013) observed a greater SGS at high altitude because of drift events due to forest fires in Nothofugus pumilio in Argentina. Similarly, the intensity of the SGS signal significantly increases with altitude along our larch altitudinal gradient.

Theoretically, the altitude and its closely related climatic variables are factors that should directly influence the SGS. Unger et al.(2011) explained that the harsh environment at high altitude may affect the reproductive system of the plant species, especially those with wide ecological amplitude. Smaller effective neighborhood size, less pollen, and seed production and a higher rate of inbreeding may be involved. At the two lowest plots $(1,700$ and $1,350 \mathrm{~m})$, the intensity of SGS was very low or non-significant. On the contrary, a significant SGS existed at the highest altitude $(2,300 \mathrm{~m})$, but its explanation is not straightforward. Among the factors affecting the intensity of SGS, the tree density within the plot (no. trees/ha) can either increase or decrease this intensity (Troupin et al. 2006). In our study, however, the stand density does not explain differences of SGS because it is approximately the same on the plots at 2,300 and 1, $700 \mathrm{~m}$ (365 and 354 trees per hectare, respectively), whereas their SGS are significantly different. Similarly, the rate of inbreeding cannot explain the SGS differences since $F_{\text {IS }}$ at each plot was not or only slightly significant, indicating no consanguinity between the altitudinal levels. By cons, we have no information on possible variation in pollen and seed production between altitudinal levels.

The very low or absence of SGS signal in the two lowest plots, interpreted as a random spatial distribution of genotypes, may be, to some extent, explained by human intervention. As suggested by the Cassini maps (http://www. geoportail.gouv.fr/accueil), all plots were certainly covered by forest at the end of the eighteenth century $(1,777)$. According to the local forest service, all along the nineteenth and twentieth centuries, small numbers of seedlings of local origin were occasionally planted in empty patches in case of irregular natural regeneration (C. Ruth and F. Bottin, personal communication). This is consistent with the lower tree age variability at $1,350 \mathrm{~m}$. These plantations were more frequent under $2,000 \mathrm{~m}$ because of easier access. The low differentiation and the lack of difference in genetic diversity between the plots along the gradient support the idea that the seeds were locally collected on a large number of individuals.

On the contrary, the non-random spatial distribution of the genotypes at the highest plot $(2,300 \mathrm{~m})$ suggests that the trees' spatial distribution is shaped by natural seed dispersal. This type of SGS and the much lower average age for this plot might indicate a recent colonization, which might coincide with abandonment of high altitude pasture land following rural exodus. Rural exodus was maximal in these regions from the end of the nineteenth century to the middle of the twentieth century. The higher intensity of SGS at 2,300 m could be the result of a relatively recent natural regeneration following abandonment of a scarcely forested pasture. The mean age of the trees in this plot is consistent with that hypothesis. This hypothesis is also consistent with the pioneer characteristics of L. decidua and its ability to colonize virgin soils.

It is likely that this recent colonization could have occurred without causing a genetic differentiation along the altitudinal gradient and without any loss of genetic diversity as already demonstrated by Pluess (2011). Consistently with this hypothesis, the higher plot also shows a higher number of pairs of loci with a linkage disequilibrium that could be caused by smaller effective population size (Flint-Garcia et al. 2003). Moreover, the lowest value of diversity and allelic richness associated with the lowest number of rare alleles at the highest altitude is consistent with a genetic drift at 2,300 $\mathrm{m}$ as rare alleles could have disappeared during the sampling accompanying the colonization. Therefore, based on several characteristics such as SGS, genetic differentiation, linkage disequilibrium, and age distribution, our interpretation of the genetic structure along the gradient is that the plot at 2,300 $\mathrm{m}$ presents a different genetic dynamic corroborating the recent colonization suggested above. A founder effect has been observed at high altitude in L. decidua (Zhao et al. 2001) along an altitudinal gradient, identified by a decrease in genetic diversity. On the contrary, the plot at 2,000 $\mathrm{m}$ with no linkage disequilibrium, a greater average age, and a lower SGS probably originates from an old establishment, whereas the two lowest plots were probably partly planted. Thereby, we hypothesize that the difference of SGS along the altitudinal gradient is mostly not related to the increased harshness of the environment with altitude but rather to human activities and to a recent colonization.

\subsection{Conclusion}

In our study, we observed differences in within-population SGS between the four altitudinal plots, with an increase of SGS related to altitude. This result suggests that different dynamics may have shaped the genetic diversity within each altitudinal level. However, our study does not have the power to separate the effect and the intensity of the natural processes related with the environmental gradient on the intensity on the SGS from the human interventions. Our study demonstrates that different dynamics of genetic diversification may occur at each altitudinal level despite the existence of a uniform structure of genetic diversity along the altitudinal gradient. The low genetic differentiation observed between the altitudinal plots implies that we should consider the larch stand distributed along the gradient as a single population. It also suggests a strong intensity of gene flow between the different altitudinal levels. Human interference and demographic events such as a founder effect seem to have a weak impact on the overall 
genetic structure. Finally, our study highlighted a high level of genetic diversity, which is consistent with the other studies on larch species and in general on forest tree species. Genetic diversity of plant resource is essential to allow populations to respond to environmental modifications. Further studies are necessary to tell whether different responses to environmental modifications are adaptive and to precisely estimate this adaptive potential, especially studies aiming at identifying the relevant adaptive traits and at measuring their environmental and genetic determinism.

Acknowledgments We thank Stefanie Wagner for developing and providing the microsatellite markers, Bruno Fady for reviewing the article and providing pieces of advice, Ruth Noble for editing the English language, Micheline Eimberck for sampling and analyzing the soil, and Catherine Bastien and Vincent Ségura for delivering pieces of scientific advices. We thank all the people who participated to the field work, including Kevin Ader, Bérangère Bougué, Jean-Paul Charpentier, Philippe Label, Thibault Laisné, Alejandro Martinez, Nathalie Mayeur, Frédéric Millier, and Anne-Sophie Sergent.

Funding This study was funded by several research grants provided by the following:

- The French Ministry of Agriculture (project Dendro PAF)

- The French Ministry of Ecology (project GICC GRAAL 10MCGOT-GICC-8-CVS-139)

- The European Research Project BACCARA, grant accession number 226299

- The France-Argentina bilateral research project ECOS-Sud A08B01

The $\mathrm{PhD}$ grant of Maxime Nardin was funded by the Region Centre and by the EFPA Department of INRA.

\section{References}

Alberto F, Niort J, Derory J et al (2010) Population differentiation of sessile oak at the altitudinal front of migration in the French Pyrenees. Mol Ecol 19:2626-2639

Austerlitz F, Dick CW, Dutech C et al (2004) Using genetic markers to estimate the pollen dispersal curve. Mol Ecol 13:937-954

Chapuis M-P, Estoup A (2007) Microsatellite null alleles and estimation of population differentiation. Mol Biol Evol 24:621-631

Collignon AM, Favre JM (2000) Contribution to the postglacial history at the western margin of Picea abies' natural area using RAPD markers. Ann Bot 85:713-722. doi:10.1006/anbo.2000.1119

Comps B, Thiebaut B, Sugar I et al (1991) Genetic variation of the Croatian beech stands (Fagus sylvatica $\mathrm{L}$ ): spatial differentiation in connection with the environment. Ann Sci For 48:15-28. doi: 10.1051/forest: 19910102

Dempster A, Laird N, Rubin D (1977) Maximum likelihood from incomplete data via EM algorithm. J R Stat Soc Ser B-Methodol 39:1-38

El Mousadik A, Petit RJ (1996) High level of genetic differentiation for allelic richness among populations of the argan tree [Argania spinosa (L.) Skeels] endemic to Morocco. Theor Appl Genet 92: 832-839

Excoffier L, Laval G, Schneider S (2005) Arlequin (version 3.0): an integrated software package for population genetics data analysis. Evol Bioinform 1:47-50

Flint-Garcia SA, Thornsberry JM, Buckler ES IV (2003) Structure of linkage disequilibrium in plants. Annu Rev Plant Physiol Plant
Mol Biol 54:357-374. doi:10.1146/annurev.arplant.54.031902. 134907

Hamrick J (2004) Response of forest trees to global environmental changes. For Ecol Manag 197:323-335. doi:10.1016/j.foreco.2004.05. 023

Hamrick JL, Godt MJW, Sherman-Broyles SL (1992) Factors influencing levels of genetic diversity in woody plant species. New For 6:95124. doi:10.1007/BF00120641

Hardy OJ, Vekemans X (2002) spagedi: a versatile computer program to analyse spatial genetic structure at the individual or population levels. Mol Ecol Notes 2:618-620

Hardy OJ, Maggia L, Bandou E et al (2006) Fine-scale genetic structure and gene dispersal inferences in 10 Neotropical tree species. Mol Ecol 15:559-571. doi:10.1111/j.1365-294X.2005.02785.x

Kalinowski ST (2005) hp-rare 1.0: a computer program for performing rarefaction on measures of allelic richness. Mol Ecol Notes 5:187189

Khasa DP, Jaramillo-Correa JP, Jaquish B, Bousquet J (2006) Contrasting microsatellite variation between subalpine and western larch, two closely related species with different distribution patterns. Mol Ecol 15:3907-3918

King GM, Gugerli F, Fonti P, Frank DC (2013) Tree growth response along an elevational gradient: climate or genetics? Oecologia 173: $1587-1600$

Körner C (2007) The use of "altitude" in ecological research. Trends Ecol Evol 22:569-574

Kremer A (1994) Diversité génétique et variabilité des caractères phénotypiques chez les arbres forestiers. Genet Sel Evol 26:S105123s. doi:10.1186/1297-9686-26-S1-S105

Kurt Y, González-Martínez SC, Alía R, Isik K (2012) Genetic differentiation in Pinus brutia Ten. using molecular markers and quantitative traits: the role of altitude. Ann For Sci 69:345-351

Lefèvre F, Boivin T, Bontemps A et al (2013) Considering evolutionary processes in adaptive forestry. Ann For Sci 71:723-739

Loiselle BA, Sork VL, Nason J, Graham C (1995) Spatial genetic structure of a tropical understory shrub, Psychotria officinalis (Rubiaceae). Am J Bot 82:1420-1425. doi:10.2307/2445869

Maghuly F, Pinsker W, Praznik W et al (2006) Genetic diversity in managed subpopulations of Norway spruce [Picea abies (L.) Karst.]. For Ecol Manag 222:266-271

Maier J (1992) Genetic variation in European larch (Larix decidua Mill). Ann Sci For 49:39-47. doi:10.1051/forest:19920104

Manel S, Joost S, Epperson BK et al (2010) Perspectives on the use of landscape genetics to detect genetic adaptive variation in the field. Mol Ecol 19:3760-3772

Mathiasen P, Premoli AC (2013) Fine-scale genetic structure of Nothofagus pumilio (lenga) at contrasting elevations of the altitudinal gradient. Genetica 141:95-105. doi:10.1007/s10709-013-97096

Migliavacca M, Cremonese E, Colombo R et al (2008) European larch phenology in the Alps: can we grasp the role of ecological factors by combining field observations and inverse modelling? Int $\mathbf{J}$ Biometeorol 52:587-605

Mosca E, Eckert AJ, Di Pierro EA et al (2012) The geographical and environmental determinants of genetic diversity for four alpine conifers of the European Alps. Mol Ecol 21:5530-5545. doi:10.1111/ mec. 12043

Moser L, Fonti P, Buentgen U et al (2010) Timing and duration of European larch growing season along altitudinal gradients in the Swiss Alps. Tree Physiol 30:225-233

Müller-Starck G, Ziehe M et al (1991) Genetic variation in European populations of forest trees. Sauerländer's Verlag, JD

Nanson A (2004) Génétique et amélioration des arbres forestiers. Presses Agronomiques de, Gembloux 
Navascues M, Vendramin GG, Emerson BC (2008) The effect of altitude on the pattern of gene flow in the endemic Canary Island pine, Pinus canariensis. Silvae Genetica 57:357-363

Nei M (1973) Analysis of gene diversity in subdivided populations. Proc Natl Acad Sci U S A 70:3321-3323

Newton AC, Allnutt TR, Gillies ACM et al (1999) Molecular phylogeography, intraspecific variation and the conservation of tree species. Trends Ecol Evol 14:140-145

Nishimura M, Setoguchi H (2010) Homogeneous genetic structure and variation in tree architecture of Larix kaempferi along altitudinal gradients on Mt Fuji. J Plant Res 124:253-263

Nybom H (2004) Comparison of different nuclear DNA markers for estimating intraspecific genetic diversity in plants. Mol Ecol 13: 1143-1155. doi:10.1111/j.1365-294X.2004.02141.x

Oddou-Muratorio S, Vendramin GG, Buiteveld J, Fady B (2008) Population estimators or progeny tests: what is the best method to assess null allele frequencies at SSR loci? Conserv gen 10:13431347

Ohsawa T, Ide Y (2008) Global patterns of genetic variation in plant species along vertical and horizontal gradients on mountains. Glob Ecol Biogeogr 17:152-163

Peakall R, Smouse PE (2006) genalex 6: genetic analysis in Excel. Population genetic software for teaching and research. Mol Ecol Notes 6:288-295. doi:10.1111/j.1471-8286.2005.01155.x

Petit RJ, Duminil J, Fineschi S et al (2005) Invited review: comparative organization of chloroplast, mitochondrial and nuclear diversity in plant populations. Mol Ecol 14:689-701

Pluess AR (2011) Pursuing glacier retreat: genetic structure of a rapidly expanding Larix decidua population. Mol Ecol 20:473-485

Polge H (1966) Établissement des courbes de variation de la densité du bois par exploration densitométrique de radiographies d'échantillons prélevés à la tarière sur des arbres vivants: applications dans les domaines Technologique et Physiologique. Ann Sci For 23:1-206. doi:10.1051/forest/19660101

Radu RG, Curtu LA, Spârchez G et al (2014) Genetic diversity of Norway spruce [Picea abies (L.) Karst.] in Romanian Carpathians. Ann For Res 57:19-29

Rousset F (2008) genepop'007: a complete re-implementation of the genepop software for Windows and Linux. Mol Ecol Resour 8: 103-106. doi:10.1111/j.1471-8286.2007.01931.x
Scotti I, Gianpaolo P, Federica M et al (2006) Population genetics of Norway spruce (Picea abies Karst.) at regional scale: sensitivity of different microsatellite motif classes in detecting differentiation. Ann For Sci 63:485-491. doi:10.1051/forest:2006029

Scotti I, Gugerli F, Pastorelli R et al (2008) Maternally and paternally inherited molecular markers elucidate population patterns and inferred dispersal processes on a small scale within a subalpine stand of Norway spruce (Picea abies[L.] Karst.). For Ecol Manag 255: 3806-3812

Shanjani PS, Vendramin GG, Calagari M (2011) Altitudinal genetic variations among the Fagus orientalis Lipsky populations in Iran. Iran J Biotechnol 9:11-19

Sork VL, Nason J, Campbell DR, Fernandez JF (1999) Landscape approaches to historical and contemporary gene flow in plants. Trends Ecol Evol 14:219-224

Tollefsrud MM, Kissling R, Gugerli F et al (2008) Genetic consequences of glacial survival and postglacial colonization in Norway spruce: combined analysis of mitochondrial DNA and fossil pollen. Mol Ecol 17:4134-4150. doi:10.1111/j.1365-294X.2008.03893.x

Troupin D, Nathan R, Vendramin GG (2006) Analysis of spatial genetic structure in an expanding Pinus halepensis population reveals development of fine-scale genetic clustering over time. Mol Ecol 15: $3617-3630$

Unger GM, Konrad H, Geburek T (2011) Does spatial genetic structure increase with altitude? An answer from Picea abies in Tyrol. Austria Plant Syst Evol 292:133-141

Vekemans X, Hardy OJ (2004) New insights from fine-scale spatial genetic structure analyses in plant populations. Mol Ecol 13:921-935

Wagner, Stefanie (2013) L'histoire du mélèze d'Europe (Larix decidua Mill.). PhD thesis University of Bordeaux 1. http://www.theses.fr/ 2013BOR14837

Wagner S, Gerber S, Petit RJ (2012) Two highly informative dinucleotide SSR multiplexes for the conifer Larix decidua (European larch). Mol Ecol Resour 12:717-725. doi:10.1111/j.1755-0998.2012. 03139.x

Zanetto A, Kremer A (1995) Geographical structure of gene diversity in Quercus petraea (Matt.) Liebl. I. Monolocus patterns of variation. Heredity 75:506-517. doi:10.1038/hdy.1995.167

Zhao GF, Felber F, Kupfer P (2001) Genetic variation and differentiation of Larix decidua populations in Swiss Alps. Acta Bot Sin 43:731735 